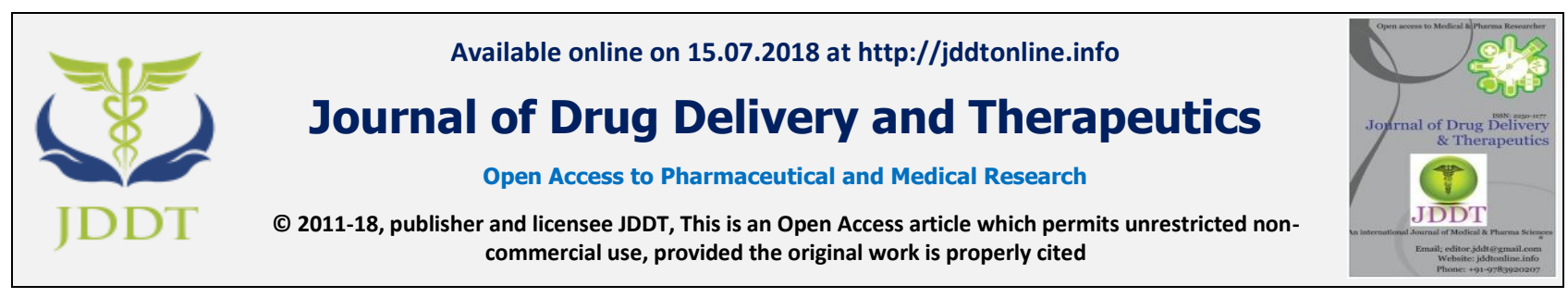

Open 2 Access

Research Article

\title{
DEVELOPMENT AND IN-VITRO EVALUATION OF CANDY BASED MEDICATED LOLLIPOPS: A NOVEL SYSTEM OF DRUG DELIVERY
}

\author{
Minakshi Rathod*, Sandesh Sul, Sachin Poharkar, Yuvraj Pandhare, Monali Muneshwar \\ MUP'S Institute of Pharmacy (D.PHARM), Pundlik Nagar Degaon, Tq-Risod Dist-Washim (444506) M.H., India
}

\section{ABSTRACT}

Lollipops or lozenges are defined as the flavored medicated dosage forms intended to be sucked and held in the mouth or pharynx containing one or more medicaments usually in the sweetened base. Lollipops are commonly used for the purpose of local or systemic effects through the buccal mucosa. Advantages of the lollipop as dosage forms include increase in bioavailability, reduction in dose size, gastric irritation and bypass first metabolism ${ }^{1}$. Lollipop is designed to improve patient compliance, acceptability, transportation etc ${ }^{2}$ The lollipops were prepared by heating and congealing method in a candy based industry with sucrose base. All the formulations prepared were subjected to various physicochemical parameters like hardness, content uniformity, friability, weight variation etc. Thickness of lollipop ranges from 12-13.2 mm. The hardness of these lollipops ranges between $10-11.5 \mathrm{~kg} / \mathrm{cm} .$. Results of in-vitro release profile indicated that formulation L3, L6, and L10 were the most promising formulations as the extent of drug release from this formulation was high as compare to other formulations up to 30 mins. The in vitro release of medicated lollipop of ambroxol $\mathrm{HCl}$ was found in the release of drug from the lollipop depends on the type and concentration of polymer used. As per all satisfactory evaluation parameters, the batch L3 is found to be optimized batch. The stability studies showed that there was no change in the formulation after 90 days. The medicated lollipops can provide an attractive alternative formulation in the treatment of mucolytics in pediatric patients.

Keywords: Amboxol HCl, Lollipops, mucolytic and mucokinetics.

Article Info: Received 07 April, 2018; Review Completed 27 June 2018; Accepted 09 July 2018; Available online 15 July 2018

Cite this article as:

Rathod M, Sul S, Poharkar S, Pandhare Y, Muneshwar M, Development and in-vitro evaluation of candy based medicated Lollipops: a novel system of drug delivery, Journal of Drug Delivery and Therapeutics. 2018; 8(4):196204 DOI: http://dx.doi.org/10.22270/jddt.v8i4.1764

*Address for Correspondence:

Minakshi Rathod, Assistant Professor, MUP'S Institute of Pharmacy (D.PHARM), Pundlik Nagar Degaon, Tq-Risod Dist-Washim (444506) M.H., INDIA

\section{INTRODUCTION}

Lollipops or lozenges are defined as the flavoured medicated dosage forms intended to be sucked and held in the mouth or pharynx containing one or more medicaments usually in the sweetened base. Lollipops are commonly used for the purpose of local or systemic effects through the buccal mucosa. Advantages of the lollipop as dosage forms include increase in bioavailability, reduction in dose size, gastric irritation and bypass first metabolism ${ }^{1}$. Lollipop is designed to improve patient compliance, acceptability, transportation etc ${ }^{2,3}$. For the past two decades, there has been an enhanced demand for more patient compliance dosage forms. As a result, the demand for their technologies has been increasing three-fold annually.
Since the development cost of a new chemical entity is very high, the pharmaceutical companies are now focusing on the development of new drug delivery systems for existing drug with an improved efficacy and bioavailability together with reduced dosing frequency to minimize side effects ${ }^{4}$. The advantages of this formulation are easy to administer to both paediatric as well as geriatric patients and Systemic absorption of drugs can be possible through buccal cavity. Drug candidates which can be incorporated in lollipop, belong to one of the following categories: Antiseptics, Local anaesthetics, Antibiotics, Antihistaminics, Antitusives, Analgesics, Decongestant, Antifungal. 


\section{Classification of lozenges}

Lozenges can be classified into various classes based on various methods like

(A) According to the site of action

(a) Local effect

Ex. Antiseptics, Decongestants.

(b) Systemic effect

Ex. Vitamins, Nicotine.

(B) According to texture and composition

(a) Chewy or caramel based medicated Lozenges

(b) Compressed tablet lozenges

(c) Soft lozenges

(d) Hard lozenges

\section{Hard Candy Lozenges or lollipop:}

Hard candy lozenges are mixtures of sugar and other carbohydrates in an amorphous (noncrystalline) or glassy state. They can also be regarded as solid syrups of sugars. The moisture content and weight of hard candy lozenge should be between, 0.5 to $1.5 \%$ and 1.5 $4.5 \mathrm{~g}$ respectively. These should undergo a slow and uniform dissolution or erosion over 5-10min., and should not disintegrate. The temperature requirements for their preparation is usually high hence heat labile materials cannot be incorporated in them ${ }^{5,6}$. The ingredients for hard candy lozenges include body agent or base which is corn syrup that is available on Baume basis. A $43^{\circ}$ Baume corn syrup is preferred in hard candy lozenges. Sweetening agents such as sucrose, dextrose, maltose and lactose are added. Acidulents are added to candy base to strengthening the flavor characteristics of the finished product. Commonly used acids are citric, tartaric, fumaric and malic acid. Colours include FD \& C colours, orange colour paste, red colour cubes etc while flavours used include menthol, eucalyptus oil, spearmint, cherry flavor etc. Medicaments up to 2-4\% can be incorporated in the hard candy lozenges. Salvage solution can be liquid or solid5.

\section{METHODS}

\section{Preformulation Studies of Drug ${ }^{7}$}

Preformulation can be defined as investigation of physical and chemical properties of drug substance alone and when combined with excipients. Preformulation studies are the first step in the rational development of dosage form of a drug substance. The goals of the program therefore are To establish the necessary physicochemical characteristics of a new drug substance. To establish its compatibility with different excipients.

\section{Characterization of Ambroxol HCL:}

\section{Organoleptic properties ${ }^{8}$}

The drug powder was analyzed for color, odor and taste.

\section{Description $^{8}$}

The drug sample (Ambroxol $\mathrm{HCl}$ ) was analyzed for physical appearance and powder nature.

\section{Melting point ${ }^{8}$}

Melting point determination of Ambroxol $\mathrm{HCl}$ was done by open capillary method. It is a good first indication of purity of sample since the presence of relatively small amount of impurity can be detected by a lowering as well as widening of melting point range.

\section{Solubility Characteristics}

A semi quantitative determination of solubility can be made by adding a solute in small incremental amount to fixed volume of solvents, phosphate buffer $\mathrm{pH} 6.8$, sparingly soluble in water, soluble in methanol, practically insoluble in methylene chloride. After each addition, the system is vigorously shaken and examined usually for any undissolve particles

\section{Spectroscopy}

\section{UV-visible Spectroscopy ${ }^{9}$}

\section{Determination of $\lambda$ max}

The UV absorption spectrum of Ambroxol HCL was obtained using a UV-visible Spectrophotometer. The spectrum was scanned from $200 \mathrm{~nm}$ to $400 \mathrm{~nm}$. A typical spectrum of Ambroxol $\mathrm{HCl}$ dissolved in phosphate buffer 6.8 (Conc. $100 \mu \mathrm{g} / \mathrm{ml}$ ) is shown in fig 2.

\section{Preparation of Standard Stock Solution}

Standard stock solution of Ambroxol Hydrochloride were prepared by dissolving $10 \mathrm{mg}$ of AMB separately in $10 \mathrm{ml}$ of $6.8 \mathrm{pH}$ Phosphate buffer solution and sonicated for 15 minutes and filtered through whatman filter paper in order to get dilution of $1 \mathrm{mg} / 1 \mathrm{ml}$ i.e. 1000 $\mu \mathrm{g} / \mathrm{ml}$.

\section{Determination of Absorption Maximas}

By appropriate dilution of standard stock solutions of Ambroxol Hydrochloride with $6.8 \mathrm{pH}$ phosphate buffer solution containing and $10 \mu \mathrm{g} / \mathrm{ml}$ of Ambroxol Hydrochloride was scanned separately in the range of 200-400nm. Wavelength of absorption maxima was determined for drugs. Ambroxol HCL showed absorption maxima one at $245 \mathrm{~nm}$.

\section{Preparation of calibration curve for Ambroxol HCL}

Concentration was made using the phosphate buffer $\mathrm{pH}$ 6.8 media. It was analyzed spectrophotometrically by measuring the absorbance at $245 \mathrm{~nm}$ wavelength. The fig 1 shows standard calibration curves with slope 0.026 and regression value 0.9999 . The curve was found to be linear in the range $2-18 \mu \mathrm{g} / \mathrm{ml}$ at the drug solution of with concentration of $100 \mu \mathrm{g} / \mathrm{ml}$ was prepared. Serial dilution $2,4 \ldots .18 \mu \mathrm{g} / \mathrm{ml}$

\section{IR Spectroscopy}

The IR spectrum of drug \& excipients was obtained in a KBR pellet using Shimadzue 206-7350038 FT-IR spectrophotometer. FT-IR spectra were recorded in the region of 400-4,000 $\mathrm{cm}^{-1}$. Assign the major absorption bands change in absorption bands indicates incompatibility between drug \& excipients. 
Formulation of medicated lollipop:

Table 1: Formulation table for medicated lollipop

\begin{tabular}{|c|c|c|c|c|c|c|c|c|c|c|c|}
\hline $\begin{array}{l}\text { Ingredients } \\
\text { In mg }\end{array}$ & LO & L1 & L2 & $\mathbf{L 3}$ & L4 & L5 & L6 & L7 & $\mathbf{L 8}$ & L9 & L10 \\
\hline Ambroxol HCl & 15 & 15 & 15 & 15 & 15 & 15 & 15 & 15 & 15 & 15 & 15 \\
\hline Sucrose & 3523 & 3490 & 3465 & 3440 & 3490 & 3465 & 3440 & 3465 & 3440 & 3465 & 3440 \\
\hline Dextrose & 1420 & 1420 & 1420 & 1420 & 1420 & 1420 & 1420 & 1420 & 1420 & 1420 & 1420 \\
\hline Citric acid & 50 & 50 & 50 & 50 & 50 & 50 & 50 & 50 & 50 & 50 & 50 \\
\hline Methyl cellulose & - & 25 & 50 & 75 & - & - & - & - & - & - & - \\
\hline Scmc & - & - & - & - & 25 & 50 & 75 & - & - & - & - \\
\hline Hpmc k100m & - & - & - & - & - & - & - & 50 & 75 & - & - \\
\hline Hpmc k4 m & - & - & - & - & - & - & - & - & - & 50 & 75 \\
\hline Colouring agent & \multicolumn{11}{|c|}{ Quantity sufficient } \\
\hline Flavouring agent & \multirow{2}{*}{\multicolumn{11}{|c|}{ Quantity sufficient }} \\
\hline Purified $\mathrm{H}_{2} \mathrm{O}$ & & & & & & & & & & & \\
\hline
\end{tabular}

\section{Preparation of syrup base:}

Syrup base was prepared by dissolving $66.66 \% \mathrm{w} / \mathrm{v}$ sucrose in purified water at $110^{\circ} \mathrm{c}$ and continuously stirring for about $90 \mathrm{~min}$.

\section{Preparation of medicated Lollipops ${ }^{10}$ :}

Medicated lollipops of $5 \mathrm{gms}$ were prepared. The Method followed for the preparation was heating and congealing technique. Syrupy base was prepared in a beaker dissolving the required amounts of sucrose in water on heating and stirring at $110^{\circ} \mathrm{C}$ for about $90 \mathrm{~min}$. Dextrose was added and stirring continued for $2 \mathrm{hrs}$ by raising the temperature to $160^{\circ} \mathrm{C}$. The material was transferred to a cooling slab and temperature was brought down $90^{\circ} \mathrm{C}$ till a plastic mass was obtained. Drug, polymer, colour, flavour were added and mixed the material for $30 \mathrm{~min}$. The material was size roped on moving rollers which were then sized into $5 \mathrm{gms}$. Lollipops and air dried for about $2 \mathrm{hrs}$. in drying chamber. The prepared lollipops were seal wrapped in polythene wrappings. An altogether three batches of formulations were prepared i.e., without added hydrocolloid, hydroxy propyl methyl cellulose (HPMC) K4M and K100M, methyl cellulose, carboxy methyl cellulose sodium salt added medicated lollipops.

\section{RESULTS AND DISCUSSION}

\section{Characterization of Ambroxol HCl}

Organoleptic characterization and Melting point determination

The physicochemical characteristics of Ambroxol HCL are described in Table 2.

Table 2: Physicochemical Characteristics of Ambroxol HCL.

\begin{tabular}{|l|l|l|}
\hline Sr. no. & Test & Observation \\
\hline 1. & Colour & $\begin{array}{l}\text { White to yellowish } \\
\text { crystalline powder }\end{array}$ \\
\hline 2. & Odour & Odourless \\
\hline 3. & Taste & Bitter \\
\hline 5. & Melting point & $233-234.5$ \\
\hline 6. & pH & $4.5-6.0$ \\
\hline
\end{tabular}

The organoleptic character and melting point was found to be as per standard drug so drug used in the formulation was found to be pure according to I.P. specification.

\section{Solubility analysis:}

Table 3: Solubility profile of Ambroxol HCl

\begin{tabular}{|l|l|l|}
\hline Sr. No. & Solvent & Solubility \\
\hline 1. & Water & Sparingly soluble \\
\hline 2. & Buffer solution 6.8 & Soluble \\
\hline 3. & Methanol & Soluble \\
\hline
\end{tabular}

The solubility of pure drug in $10 \mathrm{mg} / 10 \mathrm{ml}$ of solvent was carried out and it reveals that it is soluble in methanol, sparingly soluble in water, soluble in phosphate buffer ph 6.8 .

Standard calibration curve of ambroxol HCL in phosphate buffer 6.8:

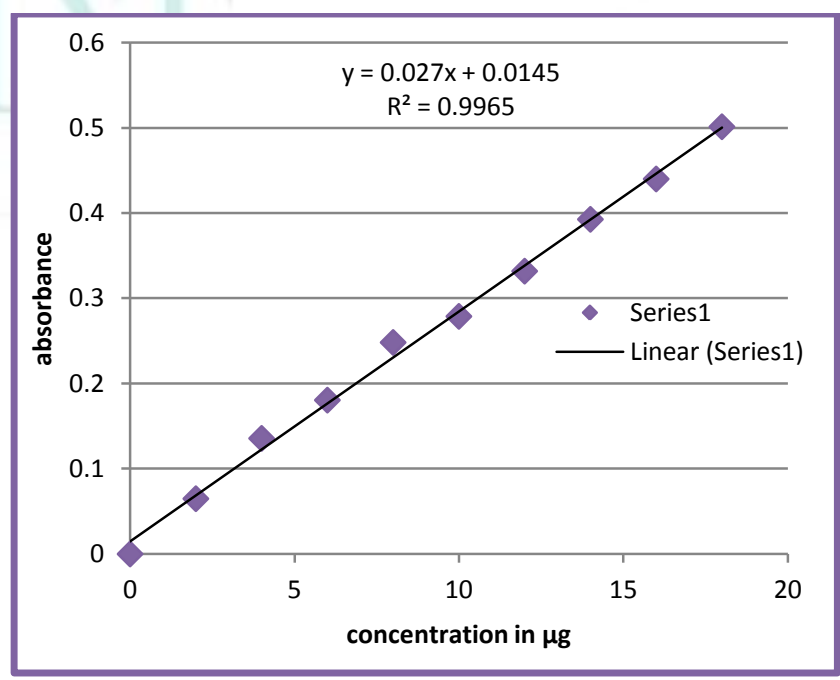

Figure 1: Calibration curve of ambroxol $\mathrm{HCl}$ in $\mathrm{pH}$ 6.8

\section{Determination of $\lambda$ max:}

The UV spectrum of ambroxol HCL in phosphate buffer 6.8 showed maximum absorption at $245 \mathrm{~nm}$. Hence drug used in the formulation was found to be pure. The UV 
spectrum of the ambroxol HCL in phosphate buffer 6.8 is given in Figure: 2.

\section{IR ANALYSIS:}

In the spectral analysis of pure ambroxol hcl, N-H streching of primary amine, C-H streching , C-5 Streching, C-H deformation, N-H out of plain bending of pure ambroxol $\mathrm{HCl}$. The ambroxol hcl with polymer was almost in the same region of the wave number ranging from $608 \mathrm{~cm}^{-1}-3402 \mathrm{~cm}^{-1}$. It showed that there was no significant interaction between the drug and polymer compatible with each other.

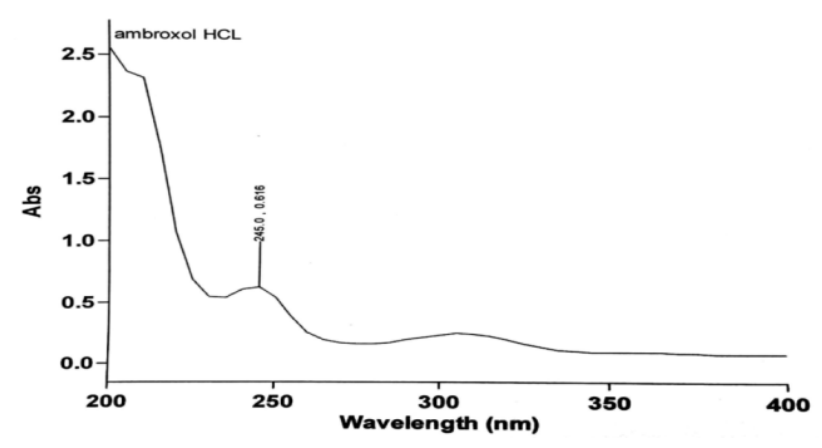

Figure 2: $\lambda_{\text {Max }}$ of ambroxol hydrochloride

\section{IR spectra of ambroxol $\mathrm{HCl}$ :}

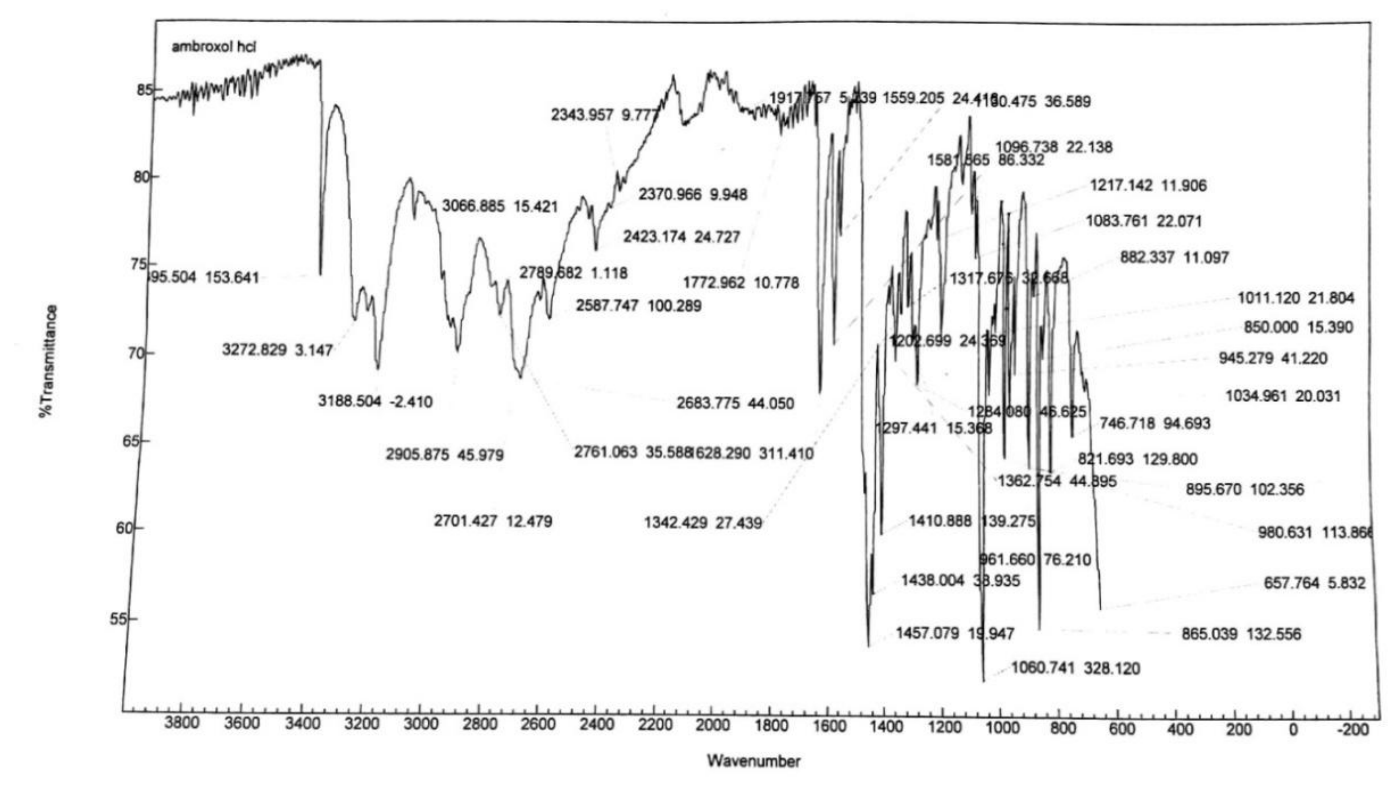

Figure 3: IR Spectra of ambroxol hydrochloride

\section{Compatibility study of Ambroxol HCl and SCMC:}

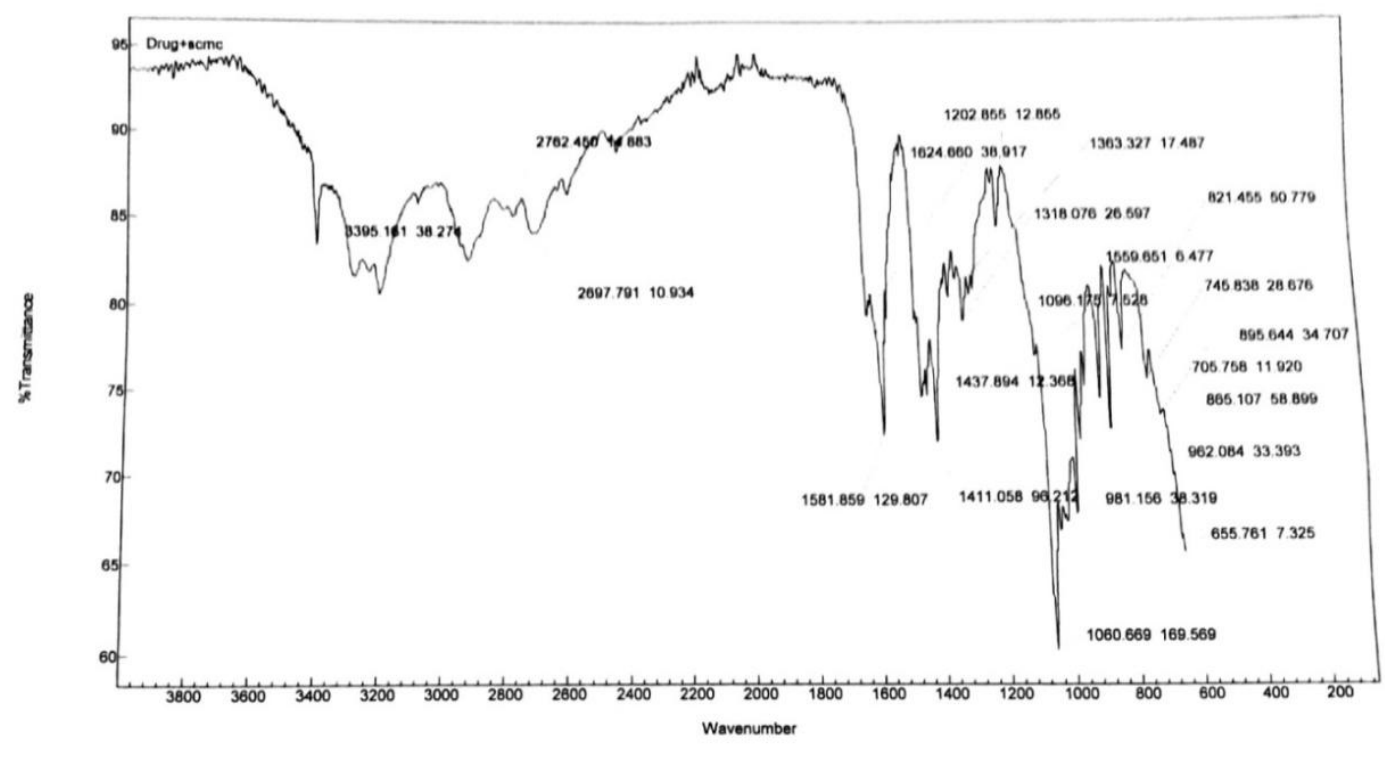

Figure 4: IR Spectra of ambroxol hydrochloride and SCMC 
Compatibility study of Ambroxol HCl and HPMC K100M

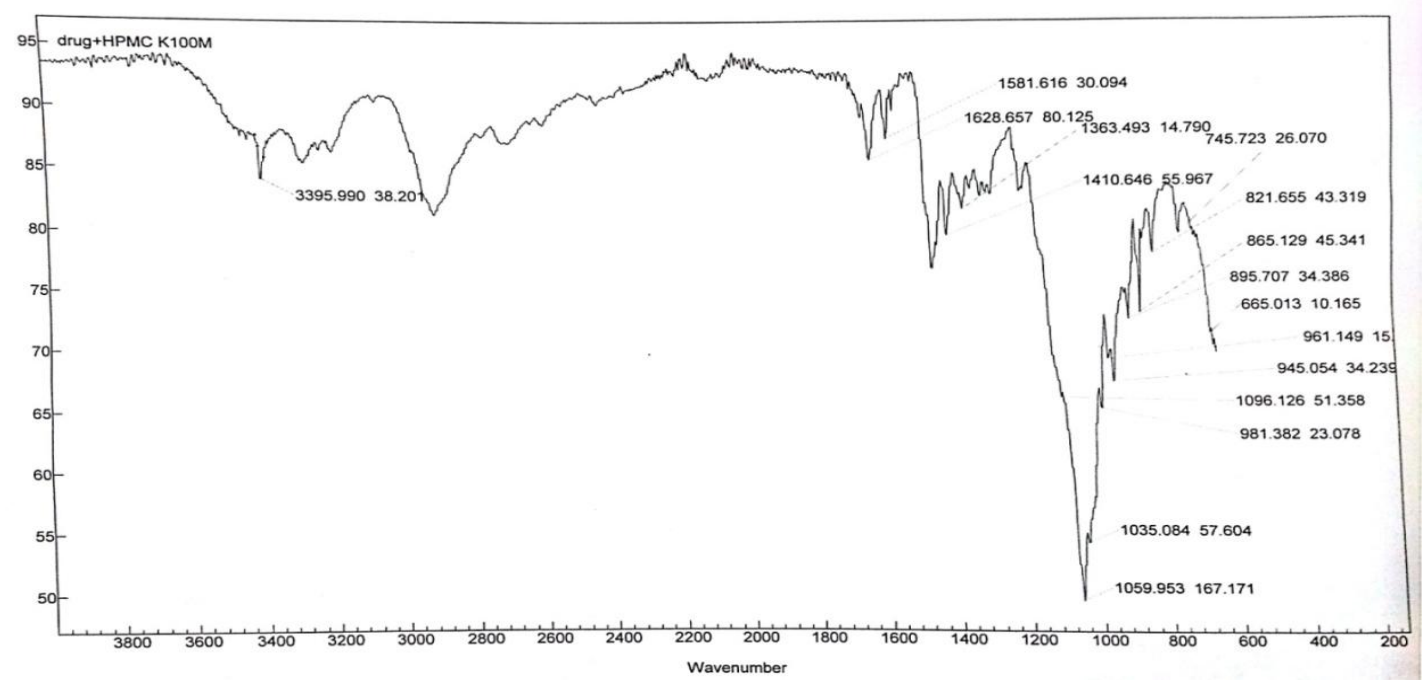

Figure 5: IR Spectra of ambroxol hydrochloride and HPMC K100M

Compatibility study of ambroxol $\mathrm{HCl}$ and HPMC K4M

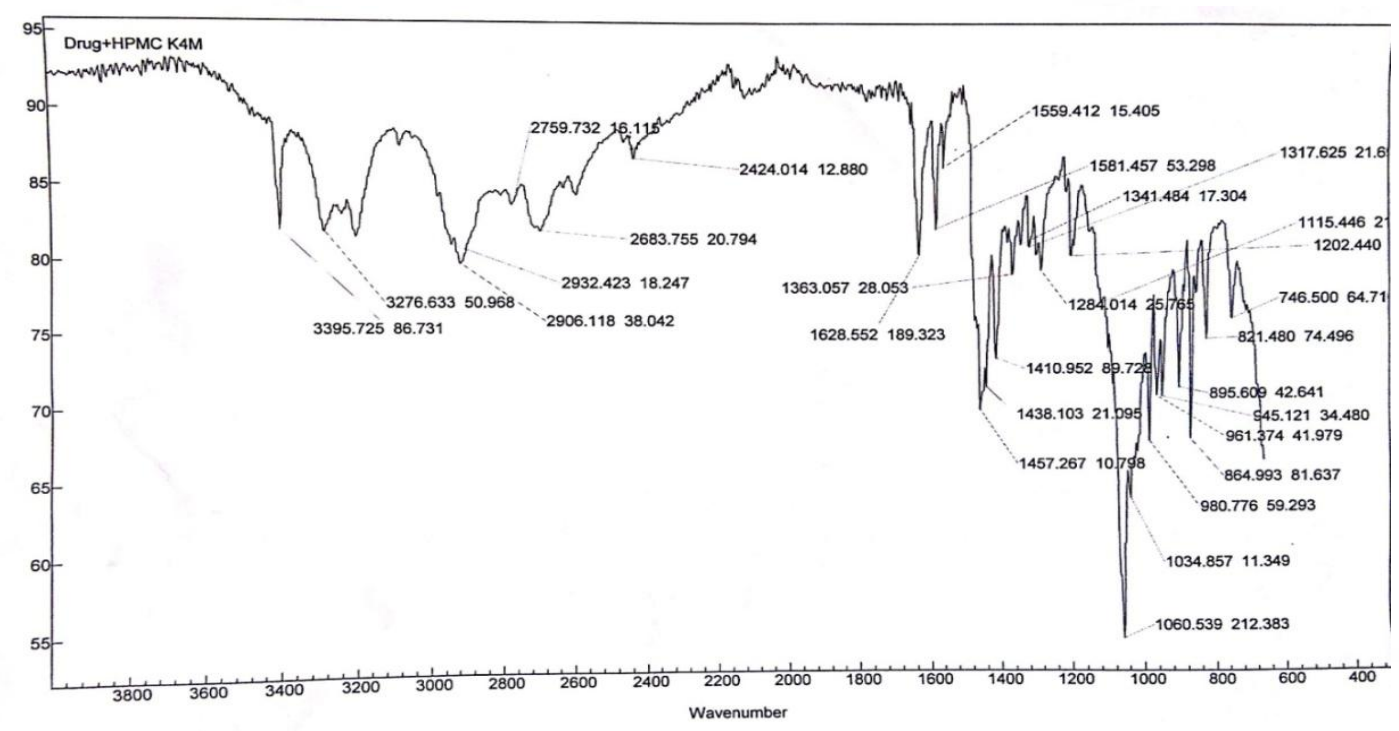

Figure 6: IR Spectra of ambroxol hydrochloride and HPMCK4M

Compatibility study of ambroxol $\mathrm{HCl}$ and methyl cellulose:

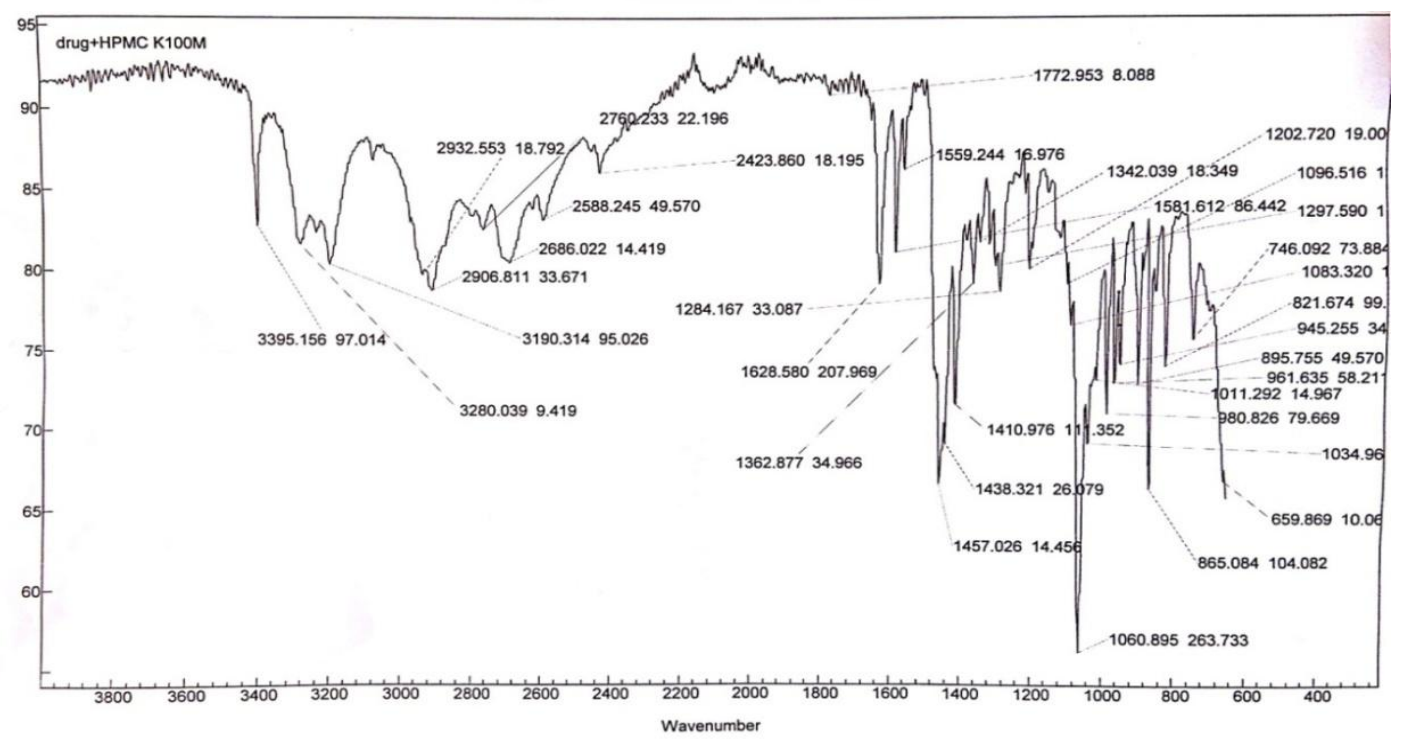

Figure 7: IR Spectra of ambroxol hydrochloride and methyl cellulose 
Characterization of prepared medicated lollipops:

Table 4: Appearance of medicated lollipops

\begin{tabular}{|c|c|}
\hline Formulation & Appearance \\
\hline L0-L10 & Orange, hard, little sticky, easily removed by mold \\
\hline
\end{tabular}

Evaluation of Ambroxol HCL medicated lollipops:

Table 5: Standard physical tests for medicated lollipops (LO-L5)

\begin{tabular}{|c|l|l|l|l|l|}
\hline Formulation & $\begin{array}{l}\text { Thickness } \\
(\mathbf{m m}) \pm \text { S.D }\end{array}$ & $\begin{array}{l}\text { Hardness } \\
(\mathbf{k g} / \mathbf{c m} \mathbf{2}) \pm \text { S.D }\end{array}$ & $\begin{array}{l}\text { Friability } \\
(\boldsymbol{\%}) \pm \text { S.D }\end{array}$ & $\begin{array}{l}\text { Weight Variation } \\
(\mathbf{g m}) \pm \text { S.D }\end{array}$ & $\begin{array}{l}\text { Moisture content } \\
\pm \text { S.D }\end{array}$ \\
\hline L0 & $12.6 \pm 0.33$ & $11 \pm 0.23$ & $0.6 \pm 0.033$ & $5 \pm 0.41$ & $0.5 \pm 0.02$ \\
\hline L1 & $13.2 \pm 0.32$ & $11 \pm 0.40$ & $0.5 \pm 0.041$ & $4.33 \pm 0.05$ & $0.6 \pm 0.06$ \\
\hline L2 & $12.7 \pm 0.38$ & $10 \pm 0.40$ & $0.7 \pm 0.012$ & $5.09 \pm 0.06$ & $0.8 \pm 0.023$ \\
\hline L3 & $12.9 \pm 0.14$ & $10.5 \pm 0.23$ & $0.56 \pm 0.044$ & $4.99 \pm 0.04$ & $0.4 \pm 0.012$ \\
\hline L4 & $12.1 \pm 0.31$ & $10.7 \pm 0.12$ & $0.74 \pm 0.061$ & $5 \pm 0.11$ & $0.6 \pm 0.052$ \\
\hline L5 & $12.6 \pm 0.12$ & $10.5 \pm 0.23$ & $0.56 \pm 0.044$ & $4.98 \pm 0.15$ & $0.42 \pm 00.11$ \\
\hline
\end{tabular}

Table 6: Standard physical tests for medicated lollipops (L6-L10)

\begin{tabular}{|c|c|c|c|c|c|}
\hline Formul $^{\text {n }}$ & Thickness(mm) \pm S.D & $\begin{array}{l}\text { Hardness } \\
(\mathrm{kg} / \mathrm{cm} 2) \pm \text { S.D }\end{array}$ & $\begin{array}{l}\text { Friability } \\
(\%) \pm \text { S.D }\end{array}$ & $\begin{array}{l}\text { Weight Variation } \\
(\mathrm{gm}) \pm \text { S.D }\end{array}$ & $\begin{array}{l}\text { Moisture content } \\
\pm \text { S.D }\end{array}$ \\
\hline L6 & $12.8 \pm 0.40$ & $11 \pm 0.23$ & $0.67 \pm 0.057$ & $4.88 \pm 0.05$ & $0.5 \pm 0.02$ \\
\hline L7 & $12.5 \pm 0.12$ & $11 \pm 0.23$ & $0.69 \pm 0.021$ & $4.9 \pm 0.12$ & $0.3 \pm 0.32$ \\
\hline L8 & $12.4 \pm 0.09$ & $10 \pm 0.23$ & $0.78 \pm 0.057$ & $5.05 \pm 0.44$ & $0.4 \pm 0.0 .23$ \\
\hline L9 & $12.0 \pm 0.37$ & $11.5 \pm 0.62$ & $0.98 \pm 0.043$ & $5 \pm 0.1$ & $0.5 \pm 0.025$ \\
\hline L10 & $12.6 \pm 0.33$ & $10 \pm 0.40$ & $0.56 \pm 0.109$ & $4.67 \pm 1.77$ & $0.6 \pm 0.11$ \\
\hline
\end{tabular}

Lollipops of all formulations (F0 to F10) were evaluated for different parameters such as thickness, hardness, weight variation, drug content and friability and results are shown in 5 and 6.

Hardness: Hardness values of the formulation ranged from $10-11.5 \mathrm{~kg} / \mathrm{cm} 2$, which indicate good strength of lollipop.

Friability: Friability values of all the formulation were less than $1 \%$, indicating good strength of lollipops. .

Weight variation: In weight variation test, the Pharmacopoeial limit for percent of deviation for tablets weighing between $5.25-4.75$ is not more than $5 \%$. The average percent deviation of all tablets was found to be within the limit and hence all formulation passes the weight variation test.

Thickness: Examination of lollipops from each batch showed flat circular shape with no cracks having orange colour. The thickness of lollipops was determined using Vernier caliper. The thickness of lollipops ranged from 12-13.2 mm. All formulations showed uniform thickness.

Moisture analysis: Moisture content in the given lollipops ranged from $0.3 \pm 0.32-0.6 \pm 0.11$.

Content uniformity: The drug content was found to be uniform among all formulation and ranged from 90.22 99.44 .

Table 7: Content uniformity of medicated lollipops (LO-L4)

\begin{tabular}{|c|c|c|c|c|c|c|c|c|c|c|}
\hline Batch no. & L0 & L1 & L2 & L3 & L4 & L5 & L6 & L7 & L8 & L9 \\
\hline $\begin{array}{l}\text { Drug content } \\
(\%) \pm \text { S.D }\end{array}$ & $\mathbf{9 6 . 9 9}$ & $\mathbf{9 6 . 5 2}$ & $\mathbf{9 5 . 6 5}$ & $\mathbf{9 9 . 4 4}$ & $\mathbf{9 8 . 2 3}$ & $\mathbf{9 3 . 2 2}$ & $\mathbf{9 7 . 6 6}$ & $\mathbf{9 5 . 4 5}$ & $\mathbf{9 6 . 7 4}$ & $\mathbf{9 3 . 3 4}$ \\
\hline
\end{tabular}

\subsection{In-vitro drug release studies:}

The dissolution rate was studied using $100 \mathrm{ml}$ for followed by phosphate buffer ( $\mathrm{pH}$ 6.8) for the remaining hours under sink condition using USP dissolution apparatus type II. The theoretical release profile calculation is important to evaluate the formulation with respect to release rates and to ascertain whether it releases the drug in predetermine manner. 


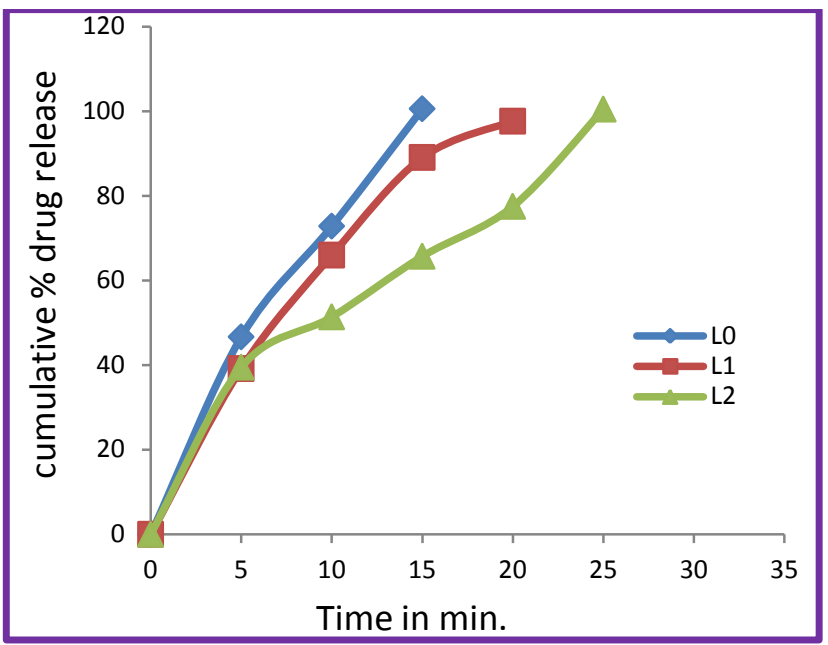

Figure 8: In-vitro dissolution profile of LO, L1 and L2 formulation

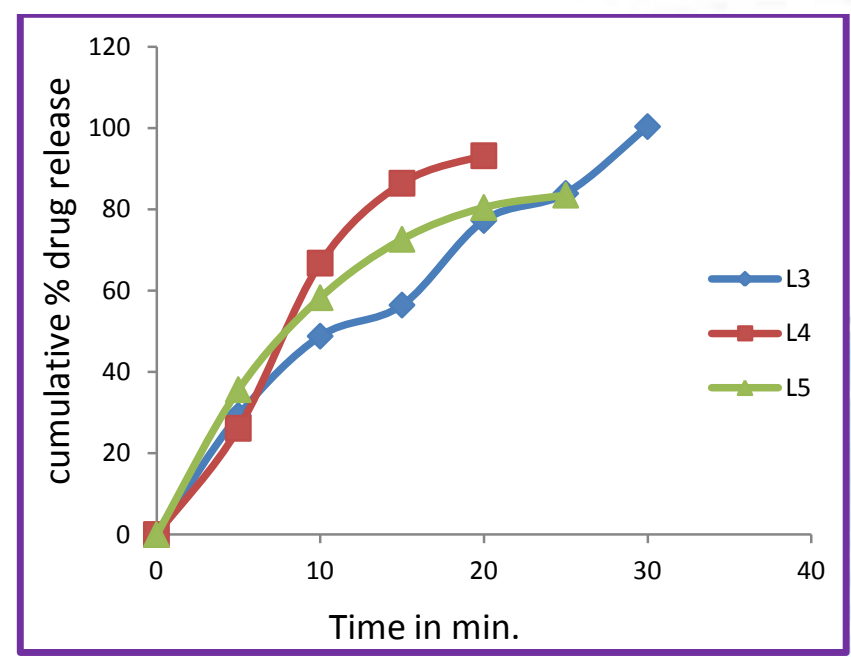

Figure 9: In-vitro dissolution profile of L3, L4 and L5formulation

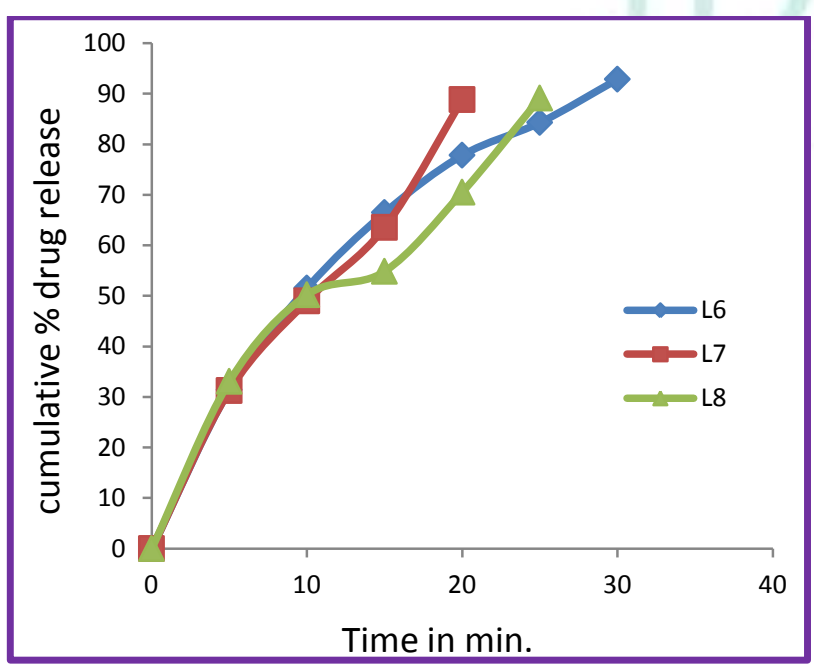

Figure 10: In-vitro dissolution profile of L6, L7 and L8formulation

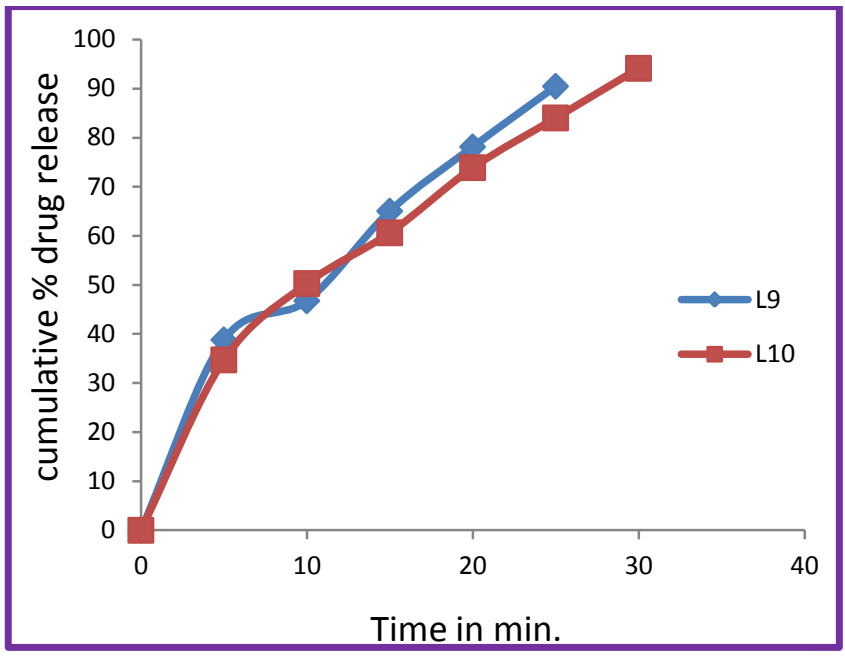

Figure 11: In-vitro dissolution profile of L9and L10 formulation

All the 11 formulation prepared were subjected to invitro release study. The in-vitro method for studying the release rate should be so that it must simulate the mouth condition. In the present work in-vitro release study was carried out using dissolution apparatus. For different time interval, sample was withdrawn and cumulative drug release was calculated. The dissolution apparatus USP II paddle type was used. The temperature was maintained at $37 \pm 0.50 \mathrm{C}$ and stirred at 100rpm. The dissolution medium being phosphate buffer of $\mathrm{pH} 6.8$. The samples were withdrawn at 5 mins interval for 30 mins. Since the drug release in the formulations F0 were faster because this batch are without polymer. Cumulative percentage drug release is calculated. The results are given in Table 8 and Figure 8 to 12. The cumulative percentage drug release of $\mathrm{LO}$ at the end of 15 minutes was found to be $100.59 \pm 0.50 \%$ at the end of 20 minutes. The release was faster in L0 than L1. L1, L2, L3 containing the methyl cellulose polymer with different conc. (25mg, 50mg, $75 \mathrm{mg}$ ). The cumulative percentage drug release of L1 $97.65 \pm 1.00$ at the end of 20 minutes, L2 was $100.05 \pm 0.16 \%$ by the end of $25 \mathrm{mins}$ and in L3 was $100.36 \pm 0.22$ at 30mins.L4, L5, L6 containing SCMC polymer with different conc. (25, $50,75 \mathrm{mg}$ ) .L4 was93.19 \pm 0.64 in $20 \mathrm{~min}$. L5 was $83.49 \pm 0.21$ and L6 was $92.86 \pm 0.40$. L7 and L8 contains HPMC K100polymer with two conc. (50mg,75mg) L7 was $88.83 \pm 0.67, \mathrm{~L} 8$ was $89.13 \pm 0.18$. L9 and L10 containing HPMC K4M with two conc. (50mg, $75 \mathrm{mg}$ ). L9 was $90.47 \pm 1.09$ and L10 was $94.14 \pm 0.38$.

Hence by the determination of the in-vitro release data, it can be concluded that the drug release was faster in case of L0 without polymer. The formulations containing Sodium carboxy methyl cellulose and Hydroxy propyl methyl cellulose K4 M \& K100M showed slower release rates when compared to M.C. The use of polymers showed extended release of the drug. Methyl cellulose $(75 \mathrm{mg}$ ) containing lollipop gives the extended release up to $30 \mathrm{~min}$ and gives the $100.36 \pm 0.22$ cumulative $\%$ drug release 
Table 8: Parameters studied on L3, L6, L10 formulations before and after stability study

\begin{tabular}{|l|l|l|l|l|l|l|}
\hline \multirow{2}{*}{ Parameters } & \multicolumn{3}{|c|}{ Before stability study } & \multicolumn{3}{c|}{ After stability study } \\
\cline { 2 - 7 } & L3 & L6 & L10 & L3 & L6 & L10 \\
\hline Thickness & $12.9 \pm 0.14$ & $12.8 \pm 0.40$ & $12.6 \pm 0.33$ & $12.9 \pm 0.14$ & $12.8 \pm 0.40$ & $12.6 \pm 0.33$ \\
\hline Hardness & $10.5 \pm 0.23$ & $11 \pm 0.23$ & $10 \pm 0.40$ & $10.5 \pm 0.23$ & $11 \pm 0.23$ & $10 \pm 0.40$ \\
\hline Drug content & $99.44 \%$ & $97.66 \%$ & $98.63 \%$ & $99.44 \%$ & $97.66 \%$ & $98.63 \%$ \\
\hline Moisture analysis & $0.4 \pm 0.012$ & $0.6 \pm 0.052$ & $0.5 \pm 0.02$ & $0.4 \pm 0.024$ & $0.6 \pm 0.045$ & $0.5 \pm 0.32$ \\
\hline
\end{tabular}

$*$ All the values are represents as Mean \pm S. D. $(n=3)$
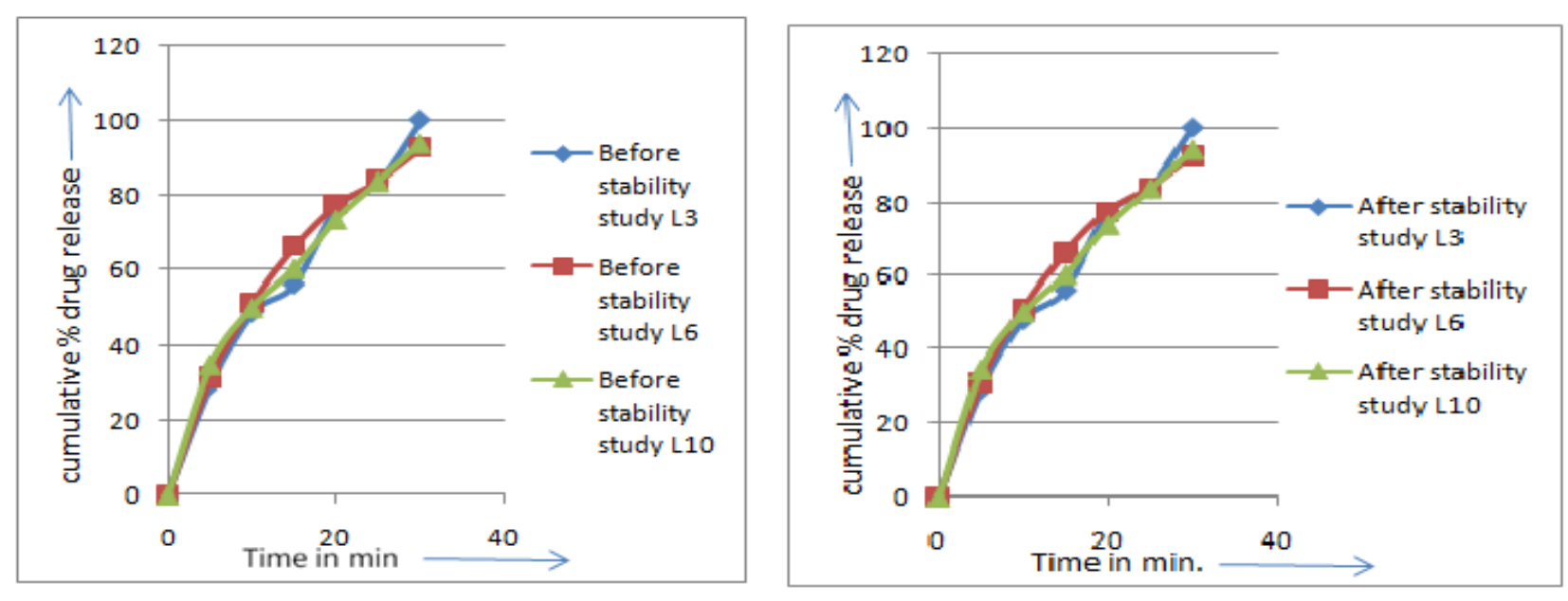

Figure 12: Dissolution profile of formulations L3, L6 and L10 before and after stability study

\section{SUMMARY}

In this present study attempt was made to prepare the medicated lollipop for peadiatrics containing mucolytic and mucokinetic ambroxol $\mathrm{HCl}$ to enhance the release rate were prepared using methyl Cellulose, HPMC K4M, HPMC K 100M \& SCMC by heating and congealing method using various ratios. The obtained Lollipops were flat spherical and uniform in shape and size.The lollipops were evaluated for various parameters. Thickness of lollipop ranges from 12-13.2 $\mathrm{mm}$. The hardness of these lollipops ranges between 10$11.5 \mathrm{~kg} / \mathrm{cm}$. Percentage buoyancy was in the range of $83.59-100.56 \%$ Results of the in vitro drug release indicated that the ambroxol $\mathrm{HCl}$ released in 30 mins. Results of in-vitro release profile indicated that formulation L3, L6, and L10 were the most promising formulations as the extent of drug release from this formulation was high as compare to other formulations up to 30 mins. The in vitro release of medicated lollipop of ambroxol $\mathrm{HCl}$ was found in the release of drug from the lollipop depends on the type and concentration of polymer used. As per all satisfactory evaluation parameters, the batch L3 is found to be optimized batch. The stability studies showed that there was no change in the formulation after 90 days.by adding the various polymers increasing the release rate by using different conc. of polymers

Thus cost effective and slow release medicated lollipop of ambroxol $\mathrm{HCl}$ in oral cavity is a safe and effective dosage form for pediatrics and having better bioavailability.

\section{CONCLUSION}

It can be concluded that medicated lollipop for pediatrics' are medicated confections designed totally deliver drug to mouth and throat for the treatment of respiratory tract infection. In the study of drug and compatibility is concluded that the drug is compatible with the polymers. The various physicochemical properties like solubility, colour, odor, taste, $\mathrm{pH}$, melting point are evaluated successfully. In in-vitro drug release analysis observed that those formulation containing polymers that gives better effect than without polymers. Formulation showed best drug release extended up to $30 \mathrm{~min}$, compatible nature and good stability, so it can be a better effective formulation in pediatrics. Formulation showed better stability than other formulation. Pediatrics attracts towards this formulation and in dysphagia this formulation are more convenient. So, these novel medicated lollipops can make better reliability for the efficient treatment.

.Most of the ambroxol $\mathrm{HCl}$ formulations are available, but by developing formulation we can improve stability of formulation, fixed dosing ,increase patient compliance \& also bioavailability of drug.

\section{Future scope}

$>$ In-vivo study

$>$ In-vivo in- vitro correlation

$>$ Formulating various formulation using different polymers those extended the drug release.

$>$ Formulating various formulation containing combination of drugs are used.

Formulating this formulation for the treatment of various problems in paediatrics. 


\section{REFERENCES}

1) Deepak R, Sanjay S. Formulation and evaluation of antianthalmentic chewable tablet. Int Pharmaceutica Sciencia 2012; 2(1):13-06.

2) Mahalaxmi R, Rajesh K, Deepak K. Investigating the suitability of isomalt and liquid glucose as sugar substitute in the formulation of salbutamol sulphate hard candy lozenges. J Chem Pharm Res 2011; 3(4):69-75.

3) Purushotham RK, Kamamia EK, Zakaullah S, Arshiya SA, Ashok KC, Anand C. Medicated lollipops of paracetamol for paediatric patients. World J Pharm Pharm Sci 2012; 1(3):1226-34.

4) Swamy PV, Gada SN, Shirsand SB, Kinagi MB, Shilpa H. Design and evaluation of cost effective orodispersible tablet of diethylcarbamazine citrate by effervescent method. Int $\mathbf{J}$ Pharm Sci Res 2010; 1(6):258-64.

5) Peters, D. (2005): Medicated Lozenges. In: Lieberman HA, Lachman L, Schwartz JB, editors. Pharmaceutical Dosage Forms: Tablets. 2nd ed. New York: Marcel Dekker, Inc.; p. 419-577.
6) Allen, LV. (200): Troches and Lozenges. Secundum Artem. Current \& Practical Compounding Information for the Pharmacist. 4 (2).

7) Lachman L, Lieberman HA, Kanig JL, The Theory and Practice of Industrial Pharmacy, Varghese Publishing House Bombay, $2^{\text {nd }}$ Ed., 171-196.

8) Martin A., Physical Pharmacy, Physical Chemical Principles in the Pharmaceutical Sciences, third edition, B.I. Waverly Pvt. Ltd, New Delhi, 557.

9) Kumar D, Singh M, Singh G, Rathore MS Spectrophotometric method development and validation for simultaneous estimation of salbutamol sulphate and Ambroxol Hydrochloride in combined dosage Forms Int. J. Drug Dev. \& Res.| 2013; 5(4): ISSN 0975-9344

10) Aparna C, Srinivas P, Duryodhan N, formulation and evaluation of medicated lozenges of albendazole for paediatric use asian journal of biochemical and pharmaceutical research, 2015; 5(3):202-215 